\title{
Tendon to bone healing and its implications for surgery
}

\author{
Daniel Lee John Bunker ${ }^{1}$ \\ Victor Ilie ${ }^{2}$ \\ Vladimir Ilie ${ }^{2}$ \\ Sean Nicklin ${ }^{3}$
}

1 Department of Surgery, Launceston General Hospital, Australia

2 University of Western Sydney, Australia

3 Consultant Plastic \& Hand Surgeon, Prince of Wales, Sydney Childrens and Sydney Hospitals, Australia

\section{Corresponding author:}

Daniel Lee John Bunker

Department of Surgery, Launceston General Hospital 274-280 Charles Street

7025 Launceston, Australia

E-mail: danielljbunker@gmail.com

\section{Summary}

Entheses are complex structures which act to reduce stress concentrations between tendon and skeleton tissues. Understanding the development and function of the enthesis organ has implications for surgical repair, particularly in regards to healing and the regulation of tendon to bone engraftment. In this paper we review the development and function of entheses as well as the enthesis organ concept. Next we examine the process of tendon to bone healing and how this can be regulated, before addressing implications for surgical repair and post-operative care.

KEY WORDS: tendon, fibrous enthesis, fibrocartilaginous enthesis, healing, surgical repair.

\section{Introduction}

The region where a tendon, ligament or joint capsule attaches to bone (an 'attachment site' or 'insertion site') is called 'enthesis'. Entheses act to balance the differing elastic moduli of tendon and skeletal tissue so that local peaks in tension are avoided, reflecting the general principle that stress concentrates at interfaces between structures with different mechanical properties. Enthesiopathies may be due to mechanical overload (tensile or compressive), systemic illness, trauma, pharmacotherapy or age-related degeneration presenting a significant burden of disease ${ }^{1,2}$.

Entheses have been most recently classified as either fibrous or fibrocartilaginous according to the character of the tissue at the bone-tendon interface (dense fibrous connective tissue or fibrocartilage, respectively) ${ }^{3-}$ 5 . This classification system reflects the embryonic development of the attachment. Previously, Woo et al. ${ }^{6}$ used the terms 'direct' and 'indirect' to describe entheses, underscoring the fact that direct (fibrocartilaginous) entheses attach directly to bone and at these sites the periosteum is absent. In the terminology promoted by the pioneering German literature in the mid-1900s, fibrous entheses equate with 'diaphyseal periosteal attachments' and fibrocartilaginous ones with 'chondroapophyseal attachments' ${ }^{7,8}$. As a general rule, regions of the appendicular skeleton with a thick layer of cortical bone are associated with fibrous entheses, whereas there may only be a thin layer of compact bone at the insertion site of fibrocartilaginous entheses. Understanding enthesis development, models of healing and the subsequent implications for surgical repair is important for many healthcare providers, particularly surgeons and rheumatologists. We provide a review of these concepts below, conducted according to the ethical standards by this journal ${ }^{9}$.

\section{Enthesis development}

Fibrous entheses are associated with some of the most powerful muscles of the body and through intramembranous ossification, whereby there is direct transformation of mesenchymal stem cells into bone tissue without a cartilage precursor. Fibroblasts and mesenchymal stem cells differentiate into osteoblasts between existing type I collagen bundles and replace the calcified matrix (bundle bone) with an organised lamellar structure. The enthesis is attached via perforating collagen fibres which are anchored directly into bone, known as Sharpey's fibres ${ }^{10}$. Sharpey's fibres arise from the tendon and periosteum and perforate into the bone substance, being restricted to regions of interstitial bone lamellae ${ }^{11}$. Such attachments can be further subdivided into two subcategories - periosteal and bony - depending on the tissue type at insertion ${ }^{11-13}$. Fibrous periosteal entheses attach to the periosteum which indirectly attaches the tendon to underlying bone, spreading the force transmitted by the tendon over a broad area and thereby reducing stress concentration. 
Conversely, fibrous bony entheses insert at points where the periosteum is absent, allowing the tendon to insert directly into the bone itself. With ageing, periosteal fibrous entheses may transform into the bony type as the periosteum is lost with bone maturation. On a dried bone specimen, points of tendon insertion via fibrous entheses generally appear as an irregular roughened area on the bone surface ${ }^{12}$.

Fibrocartilaginous entheses form via the cellular process of endochrondral ossification. The attachments are first to primordial cartilage, which is progressively replaced on its inner surface by bone. At places of ligament or tendon insertion, some cartilage is left throughout the growth period. This cartilage is eroded at the inner, bony side by endochondral ossification. The deeper area of the fibrocartilaginous enthesis is calcified and firmly linked to the bone tissue by its irregular interlocking shape and intermingling of tendinous fibres with the surface bone collagen ${ }^{14}$. Calcified fibrocartilage and bone are contiguous but form and remodel in different patterns. The cartilaginous precursor of a fibrocartilaginous enthesis is eroded at the bone side by osteoclasts and lamellar bone is deposited by osteoblasts, with some osteocytes remaining in the matrix. On the tendon side, chondrocytes deposit cartilaginous material which becomes calcified at the deeper surface ${ }^{14}$.

Biological signals from the tendon initiate growth, with subsequent development mediated by mechanical signals from attached muscle ${ }^{15}$. Microscopic examination of fibrocartilaginous entheses in dogs by Cooper and Misol ${ }^{16}$ gave rise to four transition zones: (I) tendon (or ligament) comprised of parallel collagen fibres and sparse elongated fibroblasts (tenocytes); (II) uncalcified fibrocartilage where collagen fibres continue and the surrounding cell morphology changes to rounded chondrocytes embedded in an extracellular matrix; (III) calcified fibrocartilage with characteristic mineralised extracellular matrix with perforating collagen fibres; and (IV) bone with its highly organized lamellar structure, separated from the adjacent calcified fibrocartilage via a cement line ${ }^{17}$. The characteristic histology of each zone reflects its functional purpose ${ }^{18-20}$. Zone I consists of well-aligned type I collagen fibers with small amounts of the proteoglycan decorin. The second zone is composed primarily of types II and III collagen with small amounts of types I, IX and X collagen, and the proteoglycans aggrecan and decorin. The proteoglycans themselves are interwoven between collagen and related to them by their glycosaminoglycan side chains, notably dermatin sulphate and chondroitin sulphate. Type II collagen is predominant in the third zone, combined with significant proportions of type $\mathrm{X}$ collagen as well as aggrecan. Finally, zone four consists of bone, which is made up of type I collagen and has a relatively high mineral content.

\section{The 'enthesis organ'}

Some tendon attachments are associated with an adjacent fat pad, sesamoid, fibrocartilage and/or bursa. The most well-studied of such sites is the insertion of the Achilles tendon ${ }^{21}$. This lead to the establishment of the 'enthesis organ' concept by Benjamin et al. ${ }^{3}$ who subsequently reviewed a number of tendinous attachments on the human cadaver and characterised similar enthesis organs ${ }^{22}$. The enthesis organ relates to an enthesis and the surrounding tissues which act in concert to provide stress dissipation ${ }^{3,13}$. Of note, tendons attach to bone obliquely and contact between the tendon and bone is made prior to its insertion. There can be fibrocartilage formation at this point or around associated sesamoid bones ${ }^{13}$. Examination of the skeleton reveals that there is often a bony tuberosity or pit where an enthesis organ is found ${ }^{23}$. Adipose tissue is frequently seen in association with ligament insertion and contains blood vessels and a neural supply which is postulated to provide proprioception ${ }^{23,24}$.

\section{Blood supply}

Blood supply to tendons is mainly via epitendinous blood vessels. Few vessels perforate through an enthesis as they are arrested by the calcified barrier ${ }^{10}$. The circulus articuli vasculosus, a meshwork of vasculature surrounding a joint, provides nutrient vessels to the joint structures ${ }^{25}$. This has implications for tendon and enthesis repair as it necessitates the re-apposition of surrounding soft tissue structures.

\section{Tendon failure}

Viscoelastic tendons transmit forces from skeletal muscle to inelastic bone and can be subject to tensile, compressive or shear loads. The elastic modulus of tendon is non-linear: increasing load (stress) on the tendon results in relatively greater deformation. Each zone of an enthesis consists of differing materials with an increasingly higher Young's modulus, which acts to minimise stress concentration ${ }^{18,26,27}$. Where calcified fibrocartilage joins bone, the two materials interdigitate to increase binding surface area and thereby further reduce tension peaks ${ }^{28}$. Enthesis are vulnerable to both chronic overuse and acute traumatic injuries due to their function in primary stress dissipation. Additionally, they are targeted in rheumatic autoimmune conditions (seronegative spondyloarthopathies) ${ }^{3}$. The pioneering work of Noyes et al. ${ }^{29}$ revealed three primary modes of tendon failure: through the ligament itself, at the bone underlying the enthesis (avulsion fracture) or through the tendon-bone interface. In the mature skeleton, avulsion fractures are common as the subchrondral bone underlying an enthesis is typically weaker than the transition zone between tendon and bone which is reinforced with traversing collagen fibres.

\section{Tendon to bone healing}

In general terms, tendon healing follows the process of inflammation, proliferation and repair/remodel- 
ling ${ }^{30}$. Initially, there is the formation of clot around the area of injury and the release of growth factors followed by an influx of inflammatory cells. Inflammatory cells (macrophages and neutrophils), along with tendon-derived cells, release mediators which initiate repair. There is neovascularisation, proliferation and chemotaxis of fibroblasts and collagen and extracellular matrix deposition ${ }^{31}$. Following this there is remodelling with a reduction in the vascularity and cellularity of the tissue and increased morphological organisation of the collagen. Healing between the soft tissue and bone occurs through a process of progressive re-establishment of an integrated collagen bridge. Bony integration of this interface appears to happen via progressive ossification of the extracellular matrix ${ }^{32,33}$.

There have been a number of animal studies aimed at investigating the stages of tendon to bone healing. Rodeo et al. ${ }^{34}$ studied the healing of a tendon graft in a bone tunnel while under physiologic load in a canine model. At 2 weeks, the tendon-bone interface was composed of vascular, highly cellular fibrous tissue. This granulation tissue was poorly organized with no collagen continuity between the tendon and bone. At 4 weeks, newly formed bone lined the tunnel. This new bone subsequently started to invade the fibrous interface and tendon, as demonstrated by occasional continuity of collagen fibres between the fibrous tissue and the new bone. At 12 weeks, collagen fibres connected the tendon to the surrounding bone and were aligned in the direction of the pull of the musculotendinous unit, closely resembling Sharpey's fibres. By 26 weeks, continuity between the collagen fibres of the tendon and the surrounding bone was observed throughout the length of the bone tunnel, resembling a fibrous enthesis.

In a patella reattachment model in adult sheep, the healing of the bone-tendon interface generated a fibrocartilaginous enthesis ${ }^{35}$. The healing morphology was studied using light microscopy at time intervals of $8,12,26,52$ and 104 weeks. By 8 weeks a collagen continuum was observed between tendon and bone. Despite the absence of a layer of fibrocartilage, there existed a population of cells that resembled chondrocytes at the interface between the calcified callus and tendon. The development of a callus of new bone appeared to be integral to the integrity of the remodelling soft tissue to bone interface. The associated collagen fibres between the two tissues gradually changed morphology to reflect the fibres seen in the original tendon tissue, but the fibrous tissue between the original tissue and forming enthesis remained hypercellular.

\section{Modulation of tendon to bone healing}

A key point in ligament healing is the modulation and regulation of collagen production. A primary role in this process belongs to growth factors, notably insulin-like growth factors-I and II (IGF-I and II), trans- forming growth factor $\beta$ (TGF $\beta$ ), vascular endothelial growth factor (VEGF), platelet-derived growth factor (PDGF), and basic fibroblast growth factor $(\mathrm{bFGF})^{31,36}$. All of these are upregulated during tendon and ligament healing and work in synergy to direct the repair process. Furthermore, bone morphogenic proteins (BMP), members of the TNF $\beta$ superfamily, play a role in orchestrating the remodelling of bone at the bone-tendon interface ${ }^{37}$.

Insulin-like growth factors are synthetized by a variety of tissues and act as paracrine or autocrine regulators of growth and healing. They are particularly prominent in the early phases of repair where inflammation and proliferation dominate ${ }^{36}$. In particular, they induce fibroblast migration and proliferation, as well as synthesis of collagen and extracellular matrix ${ }^{38,39}$. IGF functions synergistically with other growth factors such as PDGF to mediate proliferative effects $^{40}$. The TGF $\beta$ family has diverse anabolic and catabolic functions throughout healing. These include cell migration, collagen production and fibronectin binding as well as the regulation of cell proliferation and proteinase activity ${ }^{41-44}$. Rabbit and rat studies have shown increased expression of TGF $\beta$ or its receptor during early ligament healing $36,45,46$. It acts to upregulate the production of type II collagen in cultures of rabbit articular chondrocytes ${ }^{47}$. A rabbit model of injured medial collateral ligament tissues versus controls revealed elevated levels of TGF $\beta$, IGF-I and IGF-II at 3 weeks $^{36}$. Such growth factors are initiated early in the repair process and show long-term expression.

Vascular endothelial growth factor stimulates angiogenesis and is expressed during the proliferative and remodelling phases of tendon healing ${ }^{48-50}$. It causes the ingrowth of neovasculature from tendon vessels into the damaged area, providing a pathway for the influx of cells, cytokines, growth factors and nutrients $^{31}$. While the control of angiogenesis during normal enthesis formation is not fully understood, we can postulate that it may be similar to blood vessel development in other fibrocartilage structures, where vascular endothelial growth factor (pro-angiogenic) and endostatin (anti-angiogenic) play crucial roles ${ }^{51}$. Endostatin has been detected in adult human tendons near fibrocartilage cells and is thought to be produced in response to mechanical load ${ }^{52}$. It has been hypothesised that these cytokines work via binding to receptors on endothelial cells or extracellular matrix proteins and eliciting a secondary response in the vasculature ${ }^{53-55}$.

Platelet derived growth factor (PDGF) has been shown to stimulate type I collagen synthesis in bone cell cultures ${ }^{56}$. This growth factor has been visualised in periosteal macrophages during early bone repair. Its early expression suggests a role in initiating the healing process, and indeed PDGF has been shown to induce the production of IGF, collagen, protein and DNA 57,58 . Furthermore, basic FGF (bFGF) elicits angiogenesis, cell migration and cell proliferation ${ }^{59}$. Rat and rabbit studies of tendon repair have shown ele- 
vated bFGF derived from fibroblasts, leukocytes and tenocytes, acting to induce cellular proliferation and expediate healing ${ }^{60,61}$. Exogenous fibroblast growth factor has been shown to promote differentiation of chrondocytes $^{62}$.

Bone morphogenic proteins play a key role in tendon and fracture healing as well as osteogenesis ${ }^{63-65}$. BMP-12,13 and 14 are expressed at enthesis during embryogenesis, while BMP-2,4 and 7 play a role in osteogenesis and fracture healing ${ }^{64-67}$. Kohno et al. performed a study in rabbits using intra-articular tendon transfer for anterior cruciate ligament reconstruction to explore the role of growth factors in tendon to bone healing ${ }^{68}$. Immunohistochemical and histological examination was performed at the tendon-bone interface at 1, 3, 6 and 12 weeks after surgery. In the first 3 weeks, fibroblast growth factor 2 and vascular endothelial growth factor were found to contribute to fibrous integration, with subsequent loss of expression at 12 weeks. Bone morphogenic proteins 2 and 7 were found near the fracture and were expressed throughout the study period, regulating bone remodelling and tendino-osseous integration. Rabbit studies have employed recombinant bone morphogenic protein 2 to induce ectopic ossification in flexor digitorum communis tendons, with subsequent transfer of the bone-tendon unit to the tibia resulting in direct insertion and improved strength characteristics ${ }^{37}$.

Other important regulators of tendon to bone healing are matrix metalloproteinases (MMPs) and tissue inhibitors of matrix metalloproteinases (TIMPS). MMPs hydrolyse extracellular matrix elements and play a role in healing, angiogenesis and remodelling: their activity is regulated by TIMPS (reviewed in ${ }^{69}$ ). Knockout matrix type $1 \mathrm{MMP}$ mice have defective enthesis formation, while exploration of iatrogenic supraspinatus tears in rabbits shows MMP-2 at the site of tendon to bone healing along with TIMP-1 expression $^{70,71}$. Rabbit tenocytes have also been shown to upregulate the expression of pro-inflammatory cytokines and MMP1 gene expression after coculture with autologous leukocytes ${ }^{72}$. Regulation of MMPs and TIMPs appears to be an active and dynamic process which affects the efficiency of enthesis repair and possibly also the quality.

Studies on human tenocytes have also been performed exploring the modulation of healing rates or quality by the application of endogenous substances. The addition of platelet-rich plasma (laden with a vast array of growth factors) has been shown to abolish tenocyte inhibition and therefore improve proliferation rates in an indirect coculture system of human tenocytes $^{73}$. Proliferation has also been seen in human tenocyte cultures treated with IL-4 and IL-13, presumably due to their stimulatory effects on gene expression in fibroblastic tissues ${ }^{74,75}$. Detrimental effects of dexamethasone on cultured human tenocytes including reduced proliferative and functional capacity has been shown to be reversible with concurrent administration of PDGF76. Such findings suggest that the biological control of enthesis healing, while complex, may be manipulated through the administration of endogenous growth factors.

\section{Implications for repair}

Common surgical procedures such as Achilles tendon repair, tendon transfers, anterior cruciate ligament and rotator cuff repairs are performed to restore function and facilitate healing. Torn entheses generally heal poorly without surgical intervention. While the physical re-attachment of tendons to their site of origin restores function, the cells and vasculature involved in healing and repair derive from adjacent connective tissues and pluripotent stem cells, not from the enthesis organ itself 77,78 . Hence surgical repair must focus on the surrounding soft tissue structures as well as the failed tendon ${ }^{10}$. Importantly, the fibrocartilage associated with enthesis is in fact avascular and can impede healing after re-attachment ${ }^{13}$.

The new enthesis formed when a tendon is surgically re-attached to bone is initially fibrous ${ }^{32}$. Furthermore, tendons reattached to bone heal slowly and are of poorer quality ${ }^{79}$. Histological studies of animal models demonstrate a lack of the normal transition zones and instead the formation of scar tissue between tendon and bone, likely conferring these inferior mechanical properties ${ }^{79-81}$. Surgically anchoring periosteum onto the surface of reattached tendon promotes healing, likely due to precursor cells within the periosteum ${ }^{82}$. Additionally, re-attaching the tendon to compact bone appears to provide superior outcomes than fixation onto cancellous bone ${ }^{83,84}$.

The restoration of an enthesis can be influenced by growth modulators applied at the time of surgical repair (see Modulation of tendon to bone healing). BMP-2 has been shown to increase the rate of integration of semitendonosus grafts in rabbits undergoing anterior cruciate ligament repair ${ }^{85}$. The role of BMP-2 has also been explored in a recent study of cruciate ligament repair in rabbits using gastrocnemius tendons coated with mesenchymal stem cells from bone marrow infected with a lentivirus vector encoding the BMP-2 gene ${ }^{86}$. Biochemical and histological analysis at 4 and 8 weeks revealed elevated BMP-2 mRNA in the treated group and greater fibrocartilage formation, with more Sharpey's fibres and increased loads to failure. In a sheep model of rotator cuff repair, application of recombinant human BMP-12 at the reattachment site conferred increased stiffness and strength at 8 weeks ${ }^{67}$. Rat studies have shown that BMP-13 induces neotendon formation with fibrocartilaginous differentiation in skeletal muscle ${ }^{87}$.

Lim et al. ${ }^{88}$ showed that the application of mesenchymal stem cells to hamstring autografts for anterior cruciate ligament repair in rabbits resulted in entheses which more closely mimicked the natural state by encouraging fibrocartilage formation. A similar study in sheep has showed increased rates of healing with Osteogenic Protein-1, which increased the integrity of bone at the attachment site ${ }^{89}$. Anterior cruciate lig- 
ament replacement with a flexor tendon autograft in a canine model with concurrent application of exogenous TGF $\beta$ showed increased formation of collagen fibres bridging the tendon-bone interface at 3 weeks, with improved mechanical properties on pull-out testing $^{90}$. A rat model of medial collateral ligament repairs demonstrated improved healing with early, appropriate doses of PDGF91. A study by Bedi et al. explored the effect of a universal MMP inhibitor ( $\alpha 2$ macroglobulin) on 31 rats after supraspinatus detachment and repair ${ }^{92}$. Application of $\alpha 2$ macroglobulin showed increased fibrocartilage formation at the tendon-bone interface at 2 weeks and increased collagen production at 4 weeks compared to control animals, as well as reduced collagen degradation. Strength testing showed no significant difference between treated and control groups. Supportive findings were seen by Demiraq et al., who explored $\alpha 2$ macroglobulin injection into the knee joint of 28 rabbits after anterior cruciate ligament reconstruction with semitendinosus tendon ${ }^{93}$. Treatment revealed a beneficial effect on tendon to bone healing, with decreased levels of MMP in the joint fluid, increased numbers of Sharpey's fibers and higher loads to failure at 2 and 5 weeks.

\section{Path after repair}

For the repaired enthesis, a post-operative period of cast immobilisation followed by controlled loading seems to be appropriate. Immediately after surgery of rotator cuff tears, cast immobilisation has been shown to lead to improved mechanical properties on subsequent testing, while complete unloading or exercise has been shown to be detrimental (reviewed $i^{94}$ ). Subsequent introduction of gentle loading can be beneficial, while aggressive loading leads to impaired healing ${ }^{95}$. Rodent rotator cuff models show that the period of immobilisation leads to better organisation of collagen at the insertion site and improved viscoelastic properties ${ }^{79,96}$, while cruciate ligament models demonstrate similar results along with reduced infiltration of phagocytes ${ }^{97}$.

The emerging field of mechanobiology explores how the load applied to an enthesis influences its substructure, a concept originally proposed in relation to bone healing by Wolff in the $19^{\text {th }}$ century ${ }^{98}$. It is colloquially expressed as 'form follows function'; loads applied to a structure instigate secondary adaptive changes in the tissues at a cellular level via modulation of cytokines and growth factors and perhaps also via neural networks in the surround joint or adipose tissues. Mice studies using postnatal botulinum toxin injection into the supraspinatus muscle demonstrate impaired poor fibrocartilage formation and delayed enthesis formation with inferior mechanical properties, suggesting a central role for appropriate loading 99,100 . While heavy loading or exercise leads to impaired healing in rotator cuff models, with increased production of poor quality repair tissue ${ }^{79,101}$, con- trolled loading appears to be beneficial in optimising the integration tendon to bone ${ }^{94,102}$. A balance therefore exists between overuse, and appropriate loading after a limited period of immobilisation to improve the properties of enthesis repair through the upregulation of anabolic growth factors. Of note, flexor tendon repairs such as in the hand benefit from a different post-operative rehabilitation programme than the repaired enthesis. For tendon injuries, early commencement of passive motion after repair has been shown to be beneficial, preventing adhesions within the tendon sheath without applying excessive force which could result in rupture, and augmenting the physiological processes which orchestrate healing 103,104 .

\section{Conclusion}

Entheses are complex structures which provide a vital link between soft tissues and bone, reducing stresses and facilitating movement. Many common injuries require repair at the tendon to bone interface, however the repairs are often mechanically inferior with reduced strength characteristics. Focus should be applied to repair of the soft tissues surrounding the damaged enthesis. Modulation of healing with growth factors is also showing promise in animal models to facilitate improved characteristics. After surgical repair, immobilisation followed by gentle loading can augment the repair process.

\section{References}

1. Docking S, Samiric T, Scase E, et al. Relationship between compressive loading and ECM changes in tendons. Muscles Ligaments Tendons J. 2013;3:7-11.

2. Slobodin G, Rozenbaum M, Boulman N, et al. Varied presentations of enthesopathy. Semin Arthritis Rheum. 2007;37:119126.

3. Benjamin M, McGonagle D. The anatomical basis for disease localisation in seronegative spondyloarthropathy at entheses and related sites. J Anat. 2001;199:503-526.

4. Benjamin M, Ralphs JR. Functional and developmental anatomy of tendons and ligaments In: Gordon SL, Blair SJ,Fine LJ, eds. Repetitive Motion Disorders of the Upper Extremity. Rosemont, Illinois: American Academy of Orthopaedic Surgeons. 1995;185-203.

5. Tresoldi I, Oliva F, Benvenuto M, et al. Tendon's ultrastructure. Muscles Ligaments Tendons J. 2013;3:2-6.

6. Woo SLY, Maynard J, Butler D. Ligament, tendon and joint capsule insertion to bone In: Woo SLY, Buckwalter JA, eds. Injury and repair of the musculoskeletal soft tissues. Illinois: American Academy of Orthopaedic Surgeons. 1998;133-166.

7. Biermann $\mathrm{H}$. Ossification in the region of periosteal-diaphysial tendon- and ligament insertion. Z Zellforsch Mikrosk Anat. 1957;46:635-671.

8. Knese $\mathrm{KH}$, Biermann $\mathrm{H}$. Osteogenesis in tendon and ligament insertions in the area of the original chondral apophyses. $Z$ Zellforsch Mikrosk Anat. 1958;49:142-187.

9. Padulo J, Oliva F, Frizziero A, Maffulli N. Muscles, Ligaments and Tendons Journal. Basic principles and recommendations in clinical and field science research. MLTJ. 2013;4:250-252. 
10. Doschak MR, Zernicke RF. Structure, function and adaptation of bone-tendon and bone-ligament complexes. J Musculoskelet Neuronal Interact. 2005;5:35-40.

11. Hems T, Tillmann B. Tendon entheses of the human masticatory muscles. Anat Embryol (Berl). 2000;202:201-208.

12. Benjamin M, Kumai T, Milz S, et al. The skeletal attachment of tendons - tendon "entheses". Comp Biochem Physiol A Mol Integr Physiol. 2002;133:931-945.

13. Benjamin M, Toumi H, Ralphs JR, et al. Where tendons and ligaments meet bone: attachment sites ('entheses') in relation to exercise and/or mechanical load. J Anat. 2006;208:471-490.

14. Benjamin M, Ralphs JR. Fibrocartilage in tendons and ligaments - an adaptation to compressive load. J Anat. 1998;193 (Pt 4):481-494.

15. Blitz $E$, Viukov $S$, Sharir $A$, et al. Bone ridge patterning during musculoskeletal assembly is mediated through SCX regulation of Bmp4 at the tendon-skeleton junction. Dev Cell. 2009;17:861-873.

16. Cooper RR, Misol S. Tendon and ligament insertion. A light and electron microscopic study. J Bone Joint Surg Am. 1970;52:1-20.

17. Francois RJ. Ligament insertions into the human lumbar vertebral body. Acta Anat. 1975;91:467-480.

18. Sagarriga Visconti C, Kavalkovich K, Wu J, et al. Biochemical analysis of collagens at the ligament-bone interface reveals presence of cartilage-specific collagens. Arch Biochem Biophys. 1996;328:135-142.

19. Thomopoulos S, Williams GR, Gimbel JA, et al. Variation of biomechanical, structural, and compositional properties along the tendon to bone insertion site. J Orthop Res. 2003;21:413419.

20. Waggett AD, Ralphs JR, Kwan AP, et al. Characterization of collagens and proteoglycans at the insertion of the human Achilles tendon. Matrix Biol. 1998;16:457-470.

21. Rufai A, Ralphs JR, Benjamin M. Structure and histopathology of the insertional region of the human Achilles tendon. J Orthop Res. 1995;13:585-593.

22. Benjamin M, Moriggl B, Brenner E, et al. The "enthesis organ" concept: why enthesopathies may not present as focal insertional disorders. Arthritis Rheum. 2004;50:3306-3313.

23. Benjamin M, Redman S, Milz S, et al. Adipose tissue at entheses: the rheumatological implications of its distribution. A potential site of pain and stress dissipation? Ann Rheum Dis. 2004;63:1549-1555.

24. Shaw HM, Santer RM, Watson AH, et al. Adipose tissue at entheses: the innervation and cell composition of the retromalleolar fat pad associated with the rat Achilles tendon. J Anat. 2007;211:436-443.

25. Bray RC, Doschak MR. Blood supply and vascular responses of joint connective tissues. Current Opinion in Orthopaedics. 1995;6:125-181.

26. Butler DL, Grood ES, Noyes FR, et al. Biomechanics of ligaments and tendons. Exerc Sport Sci Rev. 1978;6:125-181.

27. Lieber RL, Brown CG, Trestik CL. Model of muscle-tendon interaction during frog seimtendinosus fixed-end contractions. Journal of Biomechanics. 1992:421-428.

28. Gao J, Rasanen T, Persliden J, et al. The morphology of ligament insertions after failure at low strain velocity: an evaluation of ligament entheses in the rabbit knee. J Anat. 1996;189 ( Pt 1):127-133.

29. Noyes FR, DeLucas JL, Torvik PJ. Biomechanics of anterior cruciate ligament failure: an analysis of strain-rate sensitivity and mechanisms of failure in primates. J Bone Joint Surg Am. 1974;56:236-253.

30. Witte MB, Barbul A. General principles of wound healing. Surg Clin North Am. 1997;77:509-528.

31. Molloy T, Wang Y, Murrell G. The roles of growth factors in tendon and ligament healing. Sports Med. 2003;33:381-394.
32. Oguma H, Murakami G, Takahashi-Iwanaga H, et al. Early anchoring collagen fibers at the bone-tendon interface are conducted by woven bone formation: light microscope and scanning electron microscope observation using a canine model. $J$ Orthop Res. 2001;19:873-880.

33. Pinczewski LA, Clingeleffer AJ, Otto DD, et al. Integration of hamstring tendon graft with bone in reconstruction of the anterior cruciate ligament. Arthroscopy. 1997;13:641-643.

34. Rodeo SA, Arnoczky SP, Torzilli PA, et al. Tendon-healing in a bone tunnel. A biomechanical and histological study in the dog. J Bone Joint Surg Am. 1993;75:1795-1803.

35. Newsham-West R, Nicholson $\mathrm{H}$, Walton $\mathrm{M}$, et al. Long-term morphology of a healing bone-tendon interface: a histological observation in the sheep model. J Anat. 2007;210:318-327.

36. Sciore P, Boykiw R, Hart DA. Semiquantitative reverse transcription-polymerase chain reaction analysis of mRNA for growth factors and growth factor receptors from normal and healing rabbit medial collateral ligament tissue. J Orthop Res. 1998;16:429-437.

37. Hashimoto Y, Yoshida G, Toyoda H, et al. Generation of tendon-to-bone interface "enthesis" with use of recombinant BMP-2 in a rabbit model. J Orthop Res. 2007;25:1415-1424.

38. Abrahamsson SO. Similar effects of recombinant human insulin-like growth factor-I and II on cellular activities in flexor tendons of young rabbits: experimental studies in vitro. J Orthop Res. 1997;15:256-262.

39. Jones Jl, Clemmons DR. Insulin-like growth factors and their binding proteins: biological actions. Endocr Rev. 1995;16:334.

40. Tsuzaki M, Brigman BE, Yamamoto J, et al. Insulin-like growth factor-I is expressed by avian flexor tendon cells. J Orthop Res. 2000;18:546-556.

41. Bennett NT, Schultz GS. Growth factors and wound healing: biochemical properties of growth factors and their receptors. Am J Surg. 1993;165:728-737.

42. Zhu X, Hu C, Zhang Y, et al. Expression of cyclin-dependent kinase inhibitors, p21cip1 and p27kip1, during wound healing in rats. Wound Repair Regen. 2001;9:205-212.

43. Marui T, Niyibizi C, Georgescu HI, et al. Effect of growth factors on matrix synthesis by ligament fibroblasts. J Orthop Res. 1997;15:18-23.

44. Wojciak B, Crossan JF. The effects of T cells and their products on in vitro healing of epitenon cell microwounds. Immunology. 1994;83:93-98.

45. Natsu-ume T, Nakamura N, Shino K, et al. Temporal and spatial expression of transforming growth factor-beta in the healing patellar ligament of the rat. J Orthop Res. 1997;15:837-843.

46. Ngo M, Pham H, Longaker MT, et al. Differential expression of transforming growth factor-beta receptors in a rabbit zone II flexor tendon wound healing model. Plast Reconstr Surg. 2001;108:1260-1267.

47. Liu SH, Yang RS, al-Shaikh R, et al. Collagen in tendon, ligament, and bone healing. A current review. Clin Orthop Relat Res. 1995:265-278.

48. Jackson JR, Minton JA, Ho ML, et al. Expression of vascular endothelial growth factor in synovial fibroblasts is induced by hypoxia and interleukin 1beta. J Rheumatol. 1997;24:12531259.

49. Boyer MI, Watson JT, Lou J, et al. Quantitative variation in vascular endothelial growth factor mRNA expression during early flexor tendon healing: an investigation in a canine model. J Orthop Res. 2001;19:869-872.

50. Gelberman RH, Khabie V, Cahill CJ. The revascularization of healing flexor tendons in the digital sheath. A vascular injection study in dogs. J Bone Joint Surg Am. 1991;73:868-881.

51. O'Reilly MS, Boehm T, Shing Y, et al. Endostatin: an endogenous inhibitor of angiogenesis and tumor growth. Cell. 1997;88:277-285. 
52. Pufe T, Petersen WJ, Miosge N, et al. Endostatin/collagen $\mathrm{XVIII}-$ an inhibitor of angiogenesis - is expressed in cartilage and fibrocartilage. Matrix Biol. 2004;23:267-276.

53. Furumatsu T, Yamaguchi N, Nishida K, et al. Endostatin inhibits adhesion of endothelial cells to collagen I via alpha(2)beta(1) integrin, a possible cause of prevention of chondrosarcoma growth. J Biochem. 2002;131:619-626.

54. Karumanchi SA, Jha V, Ramchandran R, et al. Cell surface glypicans are low-affinity endostatin receptors. Mol Cell. 2001;7:811-822.

55. Kim YM, Jang JW, Lee OH, et al. Endostatin inhibits endothelial and tumor cellular invasion by blocking the activation and catalytic activity of matrix metalloproteinase. Cancer Res. 2000;60:5410-5413.

56. Mohan S, Baylink DJ. Bone growth factors. Clin Orthop Relat Res. 1991:30-48.

57. Lynch SE, Colvin RB, Antoniades HN. Growth factors in wound healing. Single and synergistic effects on partial thickness porcine skin wounds. J Clin Invest. 1989;84:640-646.

58. Pierce GF, Mustoe TA, Lingelbach J, et al. Platelet-derived growth factor and transforming growth factor-beta enhance tissue repair activities by unique mechanisms. J Cell Biol. 1989;109:429-440.

59. Folkman J, Klagsbrun M. Angiogenic factors. Science. 1987;235:442-447.

60. Chan BP, Fu S, Qin L, et al. Effects of basic fibroblast growth factor (bFGF) on early stages of tendon healing: a rat patellar tendon model. Acta Orthop Scand. 2000;71:513-518.

61. Chang J, Most D, Thunder R, et al. Molecular studies in flexor tendon wound healing: the role of basic fibroblast growth factor gene expression. J Hand Surg Am. 1998;23:1052-1058.

62. Fujimoto E, Ochi M, Kato Y, et al. Beneficial effect of basic fibroblast growth factor on the repair of full-thickness defects in rabbit articular cartilage. Arch Orthop Trauma Surg. 1999;119:139-145.

63. Garrison KR, Shemilt I, Donell S, et al. Bone morphogenetic protein (BMP) for fracture healing in adults. Cochrane Database Syst Rev 2010:CD006950.

64. Hunziker EB, Enggist L, Kuffer A, et al. Osseointegration: the slow delivery of BMP-2 enhances osteoinductivity. Bone. 2012;51:98-106.

65. Starman JS, Bosse MJ, Cates CA, et al. Recombinant human bone morphogenetic protein-2 use in the off-label treatment of nonunions and acute fractures: a retrospective review. J Trauma Acute Care Surg. 2012;72:676-681.

66. Wolfman NM, Hattersley G, Cox K, et al. Ectopic induction of tendon and ligament in rats by growth and differentiation factors 5,6 , and 7, members of the TGF-beta gene family. J Clin Invest. 1997;100:321-330.

67. Kovacevic D, Rodeo SA. Biological augmentation of rotator cuff tendon repair. Clin Orthop Relat Res. 2008;466:622-633.

68. Kohno T, Ishibashi Y, Tsuda E, et al. Immunohistochemical demonstration of growth factors at the tendon-bone interface in anterior cruciate ligament reconstruction using a rabbit model. J Orthop Sci. 2007;12:67-73.

69. Visse R, Nagase H. Matrix metalloproteinases and tissue inhibitors of metalloproteinases: structure, function, and biochemistry. Circ Res. 2003;92:827-839.

70. Holmbeck K, Bianco P, Chrysovergis K, et al. MT1-MMP-dependent, apoptotic remodeling of unmineralized cartilage: a critical process in skeletal growth. J Cell Biol. 2003;163:661671.

71. Choi HR, Kondo S, Hirose K, et al. Expression and enzymatic activity of MMP-2 during healing process of the acute supraspinatus tendon tear in rabbits. J Orthop Res. 2002;20:927-933.

72. Al-Sadi O, Schulze-Tanzil G, Kohl B, et al. Tenocytes, pro-inflammatory cytokines and leukocytes: a relationship? Muscles Ligaments Tendons J. 2011;1:68-76.
73. Zhai W, Wang N, Qi Z, et al. Platelet-rich plasma reverses the inhibition of tenocytes and osteoblasts in tendon-bone healing. Orthopedics. 2012;35:e520-525.

74. Atamas SP. Complex cytokine regulation of tissue fibrosis. Life Sci. 2002;72:631-643.

75. Courneya JP, Luzina IG, Zeller CB, et al. Interleukins 4 and 13 modulate gene expression and promote proliferation of primary human tenocytes. Fibrogenesis Tissue Repair. 2010;3:9.

76. Wong MW, Tang YY, Lee SK, et al. Effect of dexamethasone on cultured human tenocytes and its reversibility by plateletderived growth factor. J Bone Joint Surg Am. 2003;85-A:19141920.

77. Kleiner JB, Amiel D, Roux RD, et al. Origin of replacement cells for the anterior cruciate ligament autograft. J Orthop Res. 1986;4:466-474.

78. Uhthoff HK, Trudel G, Himori K. Relevance of pathology and basic research to the surgeon treating rotator cuff disease. $J$ Orthop Sci. 2003;8:449-456.

79. Thomopoulos S, Williams GR, Soslowsky LJ. Tendon to bone healing: differences in biomechanical, structural, and compositional properties due to a range of activity levels. J Biomech Eng. 2003;125:106-113.

80. Galatz LM, Sandell LJ, Rothermich SY, et al. Characteristics of the rat supraspinatus tendon during tendon-to-bone healing after acute injury. J Orthop Res. 2006;24:541-550.

81. Thomopoulos S, Hattersley G, Rosen V, et al. The localized expression of extracellular matrix components in healing tendon insertion sites: an in situ hybridization study. J Orthop Res. 2002;20:454-463.

82. Chen $\mathrm{CH}$, Chen WJ, Shih $\mathrm{CH}$, et al. Enveloping the tendon graft with periosteum to enhance tendon-bone healing in a bone tunnel: A biomechanical and histologic study in rabbits. Arthroscopy. 2003;19:290-296.

83. Aoki M, Oguma H, Fukushima S, et al. Fibrous connection to bone after immediate repair of the canine infraspinatus: the most effective bony surface for tendon attachment. J Shoulder Elbow Surg. 2001;10:123-128.

84. Soda $Y$, Sumen $Y$, Murakami $Y$, et al. Attachment of autogenous tendon graft to cortical bone is better than to cancellous bone: a mechanical and histological study of MCL reconstruction in rabbits. Acta Orthop Scand. 2003;74:322-326.

85. Martinek V, Latterman C, Usas A, et al. Enhancement of tendon-bone integration of anterior cruciate ligament grafts with bone morphogenetic protein-2 gene transfer: a histological and biomechanical study. J Bone Joint Surg Am. 2002;84A:1123-1131.

86. Dong $Y$, Zhang $Q$, Li $Y$, et al. Enhancement of Tendon-Bone Healing for Anterior Cruciate Ligament (ACL) Reconstruction Using Bone Marrow-Derived Mesenchymal Stem Cells Infected with BMP-2. Int J Mol Sci. 2012;13:13605-13620.

87. Helm GA, Li JZ, Alden TD, et al. A light and electron microscopic study of ectopic tendon and ligament formation induced by bone morphogenetic protein-13 adenoviral gene therapy. J Neurosurg. 2001;95:298-307.

88. Lim JK, Hui J, Li L, et al. Enhancement of tendon graft osteointegration using mesenchymal stem cells in a rabbit model of anterior cruciate ligament reconstruction. Arthroscopy. 2004;20:899-910.

89. Mihelic R, Pecina M, Jelic M, et al. Bone morphogenetic protein-7 (osteogenic protein-1) promotes tendon graft integration in anterior cruciate ligament reconstruction in sheep. Am J Sports Med. 2004;32:1619-1625.

90. Yamazaki S, Yasuda K, Tomita F, et al. The effect of transforming growth factor-beta1 on intraosseous healing of flexor tendon autograft replacement of anterior cruciate ligament in dogs. Arthroscopy. 2005;21:1034-1041.

91. Batten ML, Hansen JC, Dahners LE. Influence of dosage and timing of application of platelet-derived growth factor on early 
healing of the rat medial collateral ligament. J Orthop Res. 1996;14:736-741.

92. Bedi A, Kovacevic D, Hettrich C, et al. The effect of matrix metalloproteinase inhibition on tendon-to-bone healing in a rotator cuff repair model. J Shoulder Elbow Surg. 2010;19:384-391.

93. Demirag B, Sarisozen B, Ozer O, et al. Enhancement of tendon-bone healing of anterior cruciate ligament grafts by blockage of matrix metalloproteinases. J Bone Joint Surg Am. 2005;87:2401-2410.

94. Killian ML, Cavinatto L, Galatz LM, et al. The role of mechanobiology in tendon healing. J Shoulder Elbow Surg. 2012;21:228237.

95. Thomopoulos $\mathrm{S}$. The role of mechanobiology in the attachment of tendon to bone. IBMS BoneKEy: International Bone and Mineral Society. 2011;271-285.

96. Gimbel JA, Van Kleunen JP, Williams GR, et al. Long durations of immobilization in the rat result in enhanced mechanical properties of the healing supraspinatus tendon insertion site. J Biomech Eng. 2007;129:400-404.

97. Dagher E, Hays PL, Kawamura S, et al. Immobilization modulates macrophage accumulation in tendon-bone healing. Clin Orthop Relat Res. 2009;467:281-287.
98. Wolff J. The Law of Bone Remodelling. Berlin: Springer-Verlag, 1892.

99. Thomopoulos S, Kim HM, Rothermich SY, et al. Decreased muscle loading delays maturation of the tendon enthesis during postnatal development. J Orthop Res. 2007;25:11541163.

100. Das R, Rich J, Kim HM, et al. Effects of botulinum toxin-induced paralysis on postnatal development of the supraspinatus muscle. J Orthop Res. 2011;29:281-288.

101. Peltz CD, Sarver JJ, Dourte LM, et al. Exercise following a short immobilization period is detrimental to tendon properties and joint mechanics in a rat rotator cuff injury model. J Orthop Res. 2010;28:841-845.

102. Duzgun I, Baltaci G, Atay OA. Comparison of slow and accelerated rehabilitation protocol after arthroscopic rotator cuff repair: pain and functional activity. Acta Orthop Traumatol Turc. 2011;45:23-33.

103. Boyer MI, Goldfarb CA, Gelberman RH. Recent progress in flexor tendon healing. The modulation of tendon healing with rehabilitation variables. J Hand Ther. 2005;18:80-85; quiz 86.

104. Silva MJ, Boyer MI, Gelberman RH. Recent progress in flexor tendon healing. J Orthop Sci. 2002;7:508-514. 